\title{
Open-Circuit Voltage of Organic Photovoltaics: A Time-Dependent and Unrestricted DFT Study in a
}

\section{P3HT/PCBM Complex}

J. Pablo Martínez, ${ }^{\dagger *}$ and Miquel Solà ${ }^{* *}$

† Coordinación Académica Región Altiplano, Universidad Autónoma de San Luis Potosí, Carretera Cedral km 5+600, Ejido San José de las Trojes, 78700 Matehuala, San Luis Potosi, Mexico.

¥Institut de Química Computacional i Catàlisi and Departament de Química, Universitat de Girona, C/ Maria Aurèlia Capmany, 69, 17003 Girona, Catalonia, Spain 
ABSTRACT: Solar cells based on blends of P3HT/PCMB constitute one of the most efficient polymer photovoltaic cells. One of the main factors that determine the efficiency of the solar cells is the open-circuit voltage, $V_{\text {OC. }}$ In this work, we provide an analysis of the parameters affecting the $\mathrm{V}_{\mathrm{OC}}$ in a $\mathrm{P} 3 \mathrm{HT} / \mathrm{PCBM}$ complex. Electronic transitions, excited states, and electron transfer parameters are evaluated under the classical Marcus formalism via the time-dependent and unrestricted CAM-B3LYP/6-31G* methods. The charge-recombination driving force is found to mainly affect the charge-recombination rate constant and, in turn, Voc. Even though other parameters also determine the value of $\mathrm{V}_{\mathrm{OC}}$ like density of states, dimensions of the cell, and microstructure of the donor/acceptor interface, the current work highlights the understanding attained by modeling charge-transfer parameters. The analysis reported here encourage further quantum-chemical investigations in organic photovoltaics with the aim of estimating and improving $\mathrm{V}_{\mathrm{OC}}$, such that more efficient organic solar cells may be predicted.

\section{INTRODUCTION}

A dye-sensitized solar cell (DSSC) is a photovoltaic cell with potential commercial applications that could compete with existing photovoltaic devices. ${ }^{1,2}$ DSSCs are usually $10-\mu \mathrm{m}$-thick, optically transparent films of titanium dioxide particles of a few $\mathrm{nm}$ in size, coated with a monolayer of a charge transfer (CT) dye to sensitize the films for light harvesting; as well they exhibit large current densities (in some cases greater than $12 \mathrm{~mA} \mathrm{~cm}^{-2}$ ) and exceptional stability. ${ }^{3,4}$ Fullerenes and derivatives have emerged as promising materials in the field of organic photovoltaics; the reason of that can be attributed to the fact that they are a low-cost alternative for silicon-based solar cells and they are associated to profitable manufacturing and negligible toxicity. ${ }^{5-7}$ 
A representative system for fullerene-based organic solar cells may be the complex formed by the mixture of poly(3-hexylthiophene) (P3HT) and [6,6]-phenyl-C61-butyric acid methyl ester (PCBM); several interesting studies for this complex can be found in the scientific literature. ${ }^{8-14}$ Blends like P3HT/PCBM are categorized into bulk heterojunctions; therefore, the donor and acceptor fragments are not covalently bonded..$^{15}$

The most critical feature of fullerene solar cells is their low power conversion efficiency (PCE); being the main factors affecting the PCE the open-circuit voltage $\left(V_{O C}\right)$, the short-circuit current density $\left(\mathrm{J}_{\mathrm{SC}}\right)$, and the fill factor. Hence, some theoretical and experimental studies are driven to propose novel bulk heterojunctions with increased PCE. ${ }^{7,16-18}$ Other efforts are focused on the enhancement of the PCE value and toward the comprehension of molecular parameters that primarily influence the photophysical processes involved in organic solar cells. For example, the PCE depends upon the rate constant of photoinduced CT reactions, $k_{c t}$, occurring in the P3HT/PCBM complex. In this regard, based on theoretical investigations, the $k_{c t}$ may be controlled by a few CT parameters such that these may have a direct impact on the PCE value. ${ }^{19}$ This approach represents an opportunity for the research in organic photovoltaics since the PCE can be explored by means of quantum-chemistry methodology, which is a useful tool for the evaluation of CT parameters. ${ }^{16,20-22}$

In this work, the factors affecting $k_{c t}$ in a $\mathrm{P} 3 \mathrm{HT} / \mathrm{PCBM}$ complex are analyzed from a comprehensive and insightful standpoint based on time-dependent and unrestricted density functional theory results (TDDFT and UDFT respectively); which are thought to highlight the potential research strategies to improve $\mathrm{V}_{\mathrm{OC}}$ and, in turn, the PCE. Accordingly, the quantumchemical modeling of $\mathrm{CT}$ processes at the molecular level may be challenging. ${ }^{23}$ For instance, the structural variability of the donor/acceptor interface may lead to uncertainties in the evaluation of 
electronic couplings and driving forces; on the other hand, precise estimations of the localization/delocalization dynamics of a photogenerated electron-hole pair is required since the $k_{c t}$ largely depends on them. ${ }^{24}$ Nevertheless, these and other issues are studied in the current manuscript and we consider that our results may be a guideline for future developments of organic photovoltaics characterized by enhanced PCE.

\section{COMPUTATIONAL DETAILS}

In organic solar cells, $V_{\text {OC }}$ can be expressed in terms of charge recombination as follows,

$q V_{O C}=E_{c t}-k_{B} T \log \left(\frac{q f N_{0} L}{\tau_{c t} J S}\right)$

where $k_{B} T$ is the thermal energy, $f$ is the volume fraction of the solar cell that is mixed, $N_{0}$ is the density of states in the device (it is usually around $10^{21} \mathrm{~cm}^{-3}$ for organic semiconductors), $L$ is the thickness of the solar cell, and $J_{S C}$ stands for the short-circuit density current. In addition, each CT state recombines with an average lifetime $\tau_{c t}=1 / k_{c r}$, where $k_{c r}$ is the (average) chargerecombination rate constant. Donor and acceptor materials are selected such that their electron affinities are in the $0.1-0.3 \mathrm{eV}$ energy range, thus ensuring a favorable driving force for the exciton splitting process. Such electron affinities also determine the value of $q \mathrm{~V}_{\mathrm{OC}}$ within the same energy range. As a result, the energy of a CT state can be related to $V_{O C}$ as it does in equation 1, instead of an optical gap between moieties. ${ }^{25}$

The following expression provides $k_{c r}$ as formulated under the classical Marcus theory, ${ }^{26}$

$k_{c r}=\sqrt{\frac{\pi}{\hbar^{2} \lambda k_{B} T}}\left|V_{i j}\right|^{2} \exp \left(-\frac{\left(\Delta G_{c r}+\lambda\right)^{2}}{4 \lambda k_{B} T}\right)$

here $\lambda$ is the total reorganization energy, $\Delta G_{c r}$ and $V_{i j}$ are the Gibbs energy and the electronic coupling, and $\hbar$ is the reduced Planck constant. The parameter $\lambda$ is usually divided into two 
contributions: internal $\left(\lambda_{\text {int }}\right)$ and external $\left(\lambda_{\text {ext }}\right)$ reorganization energies. All these parameters were calculated with the quantum-chemistry code Gaussian $09^{27}$ for a stable structure of the P3HT/PCBM complex, which was extracted from previous works. ${ }^{19,28,29}$ The value of $\lambda_{\text {int }}$ was also acquired from those references. Then, the geometry was reoptimized at the dispersion-corrected ${ }^{30}$ $\mathrm{PBE}^{31,32} / 6-311 \mathrm{G}^{*}$ level of theory resulting in no relevant variations. Range-separated functionals are expected to better describe excited state properties and intermolecular CT transitions. ${ }^{33,34}$ Therefore, the CAM-B3LYP/6-31G* method ${ }^{35}$ was used in all instances; yet the hexyl chain in P3HT was replaced by methyl groups to save computational resources. The hexyl group can cause torsional disorder in the P3HT fragment so that it is important in simulations; ${ }^{36}$ indeed, the complex analyzed here was optimized by considering the hexyl groups, yet they were replaced by methyl units for the calculation of CT parameters because they do not contribute to the electronic excitations under study. Additionally, the 8-unit oligomer of $\mathrm{P} 3 \mathrm{HT}$ resulted to be appropriate for the purposes of the current work; as previously discussed. ${ }^{28}$

The 30 lowest-energy Franck-Condon excitations were computed via the TDDFT framework in the gas phase. Conversely, since we found several issues to include solvent effects into the TDDFT results, the UDFT formalism was used to properly incorporate changes in solvent polarization in Franck-Condon CT states via the conductor-like polarizable continuum model (CPCM); ${ }^{37,38}$ with benzonitrile as the solvent. The $\mathrm{CT}$ states were modeled by interchanging one alpha-spin HOMO localized in P3HT with one alpha-spin LUMO located in PCBM such that a self-consistent field is searched (see Figure 1); in other words, constraining the self-consistent field process to a solution for the ionic radical pair $\mathrm{P} \mathrm{HT}^{+\bullet} / \mathrm{PCBM}^{-*}$. To this end, we first perform a DFT calculation to obtain a ground-state relaxed wavefunction; then, we use the Gaussian09 standard keyword Guess $=($ Read,Alter $)$ to obtain a Franck-Condon CT state by the next process: (i) Guess $=$ Read 
recovers the ground-state wavefunction, (ii) Guess $=$ Alter specifies orbitals to be alternated from the ground-state wavefunction, and (iii) we perform a UDFT calculation keeping the modified wavefunction to reach a quadratically convergent self-consistent field solution for a CT state. This procedure was previously applied by us in a fullerene-based donor-acceptor complex. ${ }^{39}$ The resulting energy obtained through this strategy corresponds to $E_{c t}$ in equation 1 and its negative value is $\Delta G_{c r}$ in equation 2, that is the change in Gibbs energy for charge recombination.

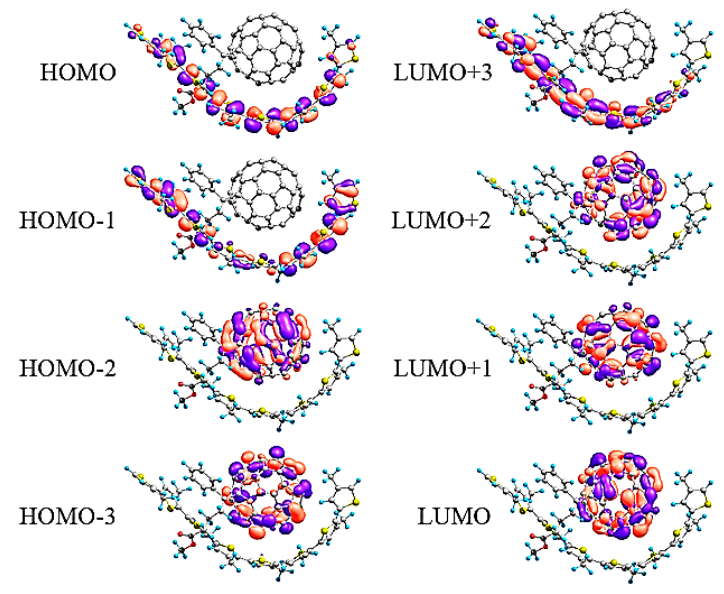

Figure 1. Ground-state electronic structure of the P3HT/PCBM complex in the gas phase.

Finally, $\lambda_{\text {ext }}$ was calculated from UDFT results as the difference between the energy of the CT state in non-equilibrium solvation and that one in equilibrium solvation. In this regard, the vanishing dipole polarization effect may be evaluated by setting a calculation in which the zerofrequency and the optical dielectric constants are equal, $\varepsilon_{s}=\varepsilon_{O P}=2.34$, an average value of the square refractive index of the $\mathrm{P} 3 \mathrm{HT} / \mathrm{PCBM}$ complex ${ }^{40,41}$ thus the resulting energy corresponds to the energy of the CT state in non-equilibrium solvation. On the other hand, the energy of the CT state in equilibrium solvation is derived from a standard CPCM calculation. The electronic 
coupling was evaluated via TDDFT calculations in the gas phase; the generalized Mulliken-Hush (GMH) method was used. ${ }^{42}$ The coupling is obtained with two charge-localized states:

$V_{i j}=\frac{\mu_{i j} \Delta E_{i j}}{\sqrt{\left(\mu_{i}-\mu_{j}\right)^{2}+4 \mu_{i j}^{2}}}$

where $\mu_{i j}$ is the transition dipole moment, $\Delta E_{i j}$ corresponds to the energy difference between states, and $\mu_{i}$ and $\mu_{j}$ are the permanent dipole moments of the ground and the excited state involved in the electronic transition.

\section{RESULTS AND DISCUSSION}

This section is aimed at the description of the electronic excitations under study, which are used in the determination of $\mathrm{CT}$ parameters and the $\mathrm{V}_{\mathrm{OC}}$ of the $\mathrm{P} 3 \mathrm{HT} / \mathrm{PCBM}$ complex. The factors affecting the accuracy of the calculations are also analyzed; as well as the performance of the implemented methodology. The impact of the current manuscript in the investigation of the efficiency of organic photovoltaics is discussed as well.

In Figure 1, the electronic structure of the $\mathrm{P} 3 \mathrm{HT} / \mathrm{PCBM}$ complex is schematized, and the description of electronic transitions is provided in Table 1. A CT state is formed after dissociation of the lowest-energy exciton entirely formed at the P3HT fragment, $\mathrm{P} 3 \mathrm{HT} / \mathrm{PCBM}$, which is characterized by an excitation energy of $2.907 \mathrm{eV}$ and $71 \%$ of a HOMO-to-LUMO+3 transition $(\mathrm{O} . \mathrm{S} .=1.35)$. This is a local excitation of $\mathrm{P} 3 \mathrm{HT}$. The CT state can be originated from a HOMOto-LUMO transition since the HOMO is fully placed at the P3HT fragment, and the LUMO is fully localized at the PCBM moiety. Table 1 illustrates that the first electronic transition corresponds to a $\mathrm{CT}$ transition $\left(\mathrm{P} \mathrm{HT}^{+\bullet} / \mathrm{PCBM}^{-*}\right)$ with an excitation energy of $2.397 \mathrm{eV}$, thus resulting in a favorable driving force for the charge separation reaction: $\mathrm{P} 3 \mathrm{HT} * / \mathrm{PCBM} \rightarrow \mathrm{P}^{*} \mathrm{HT}^{+*} / \mathrm{PCBM}^{*}$. 
Table 1. The lowest-energy electronic transitions in the P3HT/PCBM complex. Excitation energies $E x$ in eV, main HOMO (H) to LUMO (L) orbital contributions, oscillator strength O.S., and transition dipole moment $\mu_{i j}$ in debye. Results correspond to TDDFT in the gas phase

\begin{tabular}{|c|c|c|c|c|}
\hline$E x$ & \multicolumn{2}{|c|}{ Transition } & O.S. & $\mu_{i j}$ \\
\hline 2.397 & $\mathrm{H} \rightarrow \mathrm{L}$ & $(90 \%)$ & 0.000 & 0.012 \\
\hline 2.436 & $\mathrm{H}-2 \rightarrow \mathrm{L}$ & $(88 \%)$ & 0.002 & 0.097 \\
\hline 2.469 & $\mathrm{H}-2 \rightarrow \mathrm{L}+1$ & $(70 \%)$ & 0.000 & 0.003 \\
\hline & $\mathrm{H}-3 \rightarrow \mathrm{L}$ & $(15 \%)$ & & \\
\hline 2.525 & $\mathrm{H} \rightarrow \mathrm{L}+1$ & $(52 \%)$ & 0.002 & 0.088 \\
\hline & $\mathrm{H}-3 \rightarrow \mathrm{L}$ & $(38 \%)$ & & \\
\hline 2.531 & $\mathrm{H}-3 \rightarrow \mathrm{L}$ & $(40 \%)$ & 0.002 & 0.069 \\
\hline & $\mathrm{H} \rightarrow \mathrm{L}+1$ & $(40 \%)$ & & \\
\hline & $\mathrm{H}-2 \rightarrow \mathrm{L}+1$ & $(9 \%)$ & & \\
\hline $2.907 *$ & $\mathrm{H} \rightarrow \mathrm{L}+3$ & $(71 \%)$ & 1.347 & 18.90 \\
\hline & $\mathrm{H}-1 \rightarrow \mathrm{L}+5$ & $(8 \%)$ & & \\
\hline
\end{tabular}


The TDDFT energy for the resulting CT state in the gas phase is $2.397 \mathrm{eV}$ above the ground state. Solvent effects are therefore included in this CT state via UDFT calculations. As can be seen in Table 2, the difference in relative energy of the lowest-lying CT state in gas-phase calculated with TDDFT and UDFT differs by only $0.07 \mathrm{eV}$. Table 2 also collects the variation of excited state properties. Based on UDFT results, we found that the stabilization by solvent effects, $\Delta G_{\text {solv }}$, is $0.934 \mathrm{eV}$ for the CT state under study (not given in Table 2). Besides, there is a gradual increase in the dipole moment from the gas phase to the equilibrium solvation, as expected. The Mulliken charge in $\mathrm{P} 3 \mathrm{HT}$ for this $\mathrm{CT}$ state is greater than $+0.8 \mathrm{e}^{-}$, and naturally the charge in PCBM is lower than $-0.8 \mathrm{e}^{-}$; indeed, the value of $\left\langle\mathrm{S}^{2}>\right.$, the spin contamination, near to 1.0 confirms the calculation of an open-shell singlet $\mathrm{CT}$ state (i.e. $\mathrm{P} \mathrm{HT}^{+\bullet} / \mathrm{PCBM}^{-\bullet}$ ). Consequently, UDFT turns out to be a useful tool in the simulation of CT states in organic photovoltaics.

Table 2. Excited state properties for the lowest-energy charge transfer state in the P3HT/PCBM complex as calculated via UDFT. The energy relative to the gas-phase ground state (GS) $\Delta E$ is given in $\mathrm{eV}$, dipole moment $\mu$ in debye, and the total charge $\mathrm{Q}$ distributed through either the P3HT or PCBM fragment in $e^{-}$. The spin contamination is reported as $<\mathbf{S}^{2}>$

\begin{tabular}{|c|c|c|c|c|c|}
\hline Phase & $\Delta E$ & $\mu$ & Qр3нт & QPCBM & $<\mathrm{S}^{2}>$ \\
\hline GS Gas & 0.000 & 2.9 & -0.05 & +0.05 & - \\
\hline TDDFT Gas & 2.397 & 14.3 & +0.85 & -0.85 & - \\
\hline UDFT Gas & 2.327 & 15.8 & +0.88 & -0.88 & 1.08 \\
\hline NonEqSolv & 1.823 & 20.4 & +0.89 & -0.89 & 1.08 \\
\hline EqSolv ${ }^{\mathrm{a}}$ & 1.393 & 28.8 & +0.90 & -0.90 & 1.09 \\
\hline
\end{tabular}


The variables affecting $\mathrm{V}_{i j}$ for the charge recombination reaction can be collected from Tables 1-2 and equation 3 resulting in $\mathrm{V}_{i j}=2.45 \mathrm{meV}$. A previous estimation resulted in $\mathrm{V}_{i j}=13.60 \mathrm{meV}$ for the same reaction, which is an averaged value obtained from the evaluation of $\mathrm{V}_{i j}$ for different orientations of the P3HT/PCBM complex. ${ }^{19}$ However, the latter $\mathrm{V}_{i j}$ was assessed by means of a planar configuration of the P3HT moiety. It can be showed that the inclusion of dispersion corrections into the DFT methodology during the geometry optimization leads to a U-shaped configuration of the P3HT fragment, as shown in Figure 1. ${ }^{28,30}$ Based on this argument, we select the value of $2.45 \mathrm{meV}$ for the following discussion. Moreover, Table 2 provides the UDFT energies of the CT state in (non)equilibrium solvation resulting in $\lambda_{\text {ext }}=0.430 \mathrm{eV}$. According to equation 2 , variations of tens regarding $\lambda_{\text {ext }}$ change $k_{c t}$ at least in one order of magnitude; therefore, this predicament is taken into consideration in the discussion presented below. The TDDFT energy of $2.397 \mathrm{eV}$ of the CT state is stabilized due to $\Delta G_{\text {solv }}$ which results in $1.462 \mathrm{eV}$. This value is $E_{c t}$ in equation 1 and, in turn, $\Delta G_{c r}=-1.462 \mathrm{eV}$ because negligible contributions of the entropy term are assumed. The CT parameters are reported in Table 3 along with the charge-recombination rate constant, $k_{c r}=1.62 \times 10^{7} \mathrm{~s}^{-1}$; this latter is in agreement with the experimental range and it is also at least one order of magnitude slower than the rate calculated by Troisi et al. (they reported $4.86 \times 10^{8}$ $\mathrm{s}^{-1}$ and $\left.1.93 \times 10^{9} \mathrm{~s}^{-1}\right){ }^{19}$

Table 3. Charge-transfer parameters involved in the charge recombination in the P3HT/PCBM complex. Energy terms in $\mathrm{eV}$, and the rate constant in $\mathrm{s}^{-1}$

\begin{tabular}{llll}
\hline Parameter & Value & Parameter & Value \\
\hline$\lambda_{\text {int }}$ & 0.245 & $E_{c t}$ & 1.462 \\
$\lambda_{\text {ext }}$ & 0.430 & $\Delta G_{c r}$ & -1.462 \\
$\lambda$ & 0.675 & $k_{c r}$ & $1.62 \times 10^{7}$ \\
$\mathrm{~V}_{i j}$ & 0.002 & & \\
\hline
\end{tabular}


The validity of the determination of $k_{c r}$ is discussed as follows. The classical Marcus formulation is a useful tool in the evaluation of $k_{c t}{ }^{43}$ It is derived from the Fermi's golden rule at the short-time and high-temperature limits. It predicted the inverted region, where the rate constant becomes slower as the driving force increases in a more exothermic reaction. The dominant mechanism under this formalism is an activated process thus omitting quantum effects. The validity of such an approach should be proved for intramolecular CT, and it may lead to inconsistencies in the inverted region since it does not include nuclear tunneling due to overlap between nuclear wave functions. Indeed, Figure 2 shows that the intermolecular CT under study is in the inverted region; although the calculated rate is near the cusp of the plot (wherein $\left|\Delta G_{c r}\right|=\lambda$ ) so that an activated mechanism is possibly still dominant. Accordingly, the assessment of $k_{c r}$ may be considered valid because our results fit the experimental range and these are not in the far inverted regime, $\left|\Delta G_{c r}\right|$ $>>\lambda$, where quantum effects are dominant, and the Marcus expression does fail. ${ }^{44,45}$ The impact of these calculations in the open-circuit voltage along with the associated accuracy is discussed onward. 


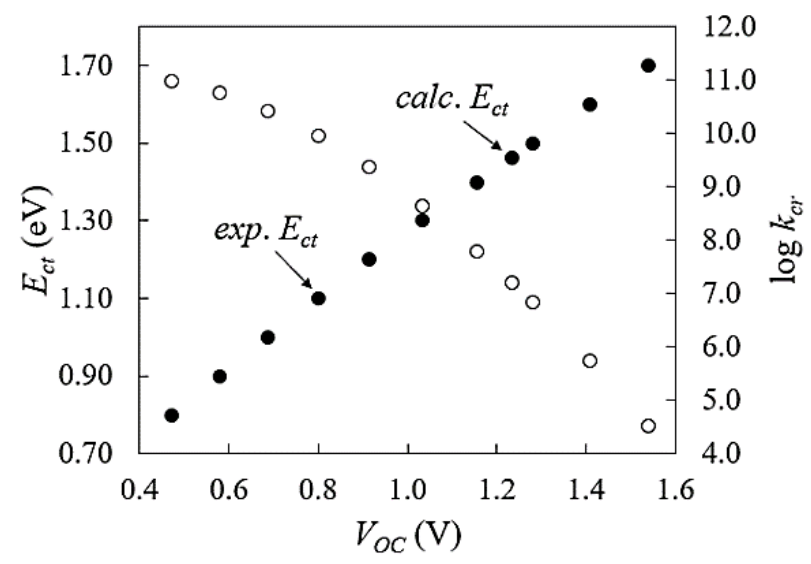

Figure 2. The lowest-energy charge transfer state, $E_{c t}$ (black filled-in circles), and the chargerecombination rate constant, $k_{c r}$ (white filled-in circles), as a function of the open-circuit voltage, Voc, of the P3HT/PCBM complex.

Table 4 collects all the data used in the calculation of $V_{\text {OC. }}$ Several parameters are constants like the thermal energy $k_{B} T$ and the elementary charge $q$. Others come from experiments such as the density of states $N_{0}$. The typical thickness of the DSSC is taken as $10 \mu \mathrm{m}$ and we assume a pure mixture of $\mathrm{P} 3 \mathrm{HT} / \mathrm{PCBM}$ such that $f=1.0$; in fact, varying $f$ from 0.1 to 1.0 has no significant effect in equation 1 (its logarithmic contribution is minor as compared to the other large numbers). The average lifetime $\tau_{c t}$ is extracted from the previous calculation of $k_{c r}$. Experimental measurements carried out in a DSSC made of P3HT/PCBM resulted in a density current of $3.0 \mathrm{~mA} \mathrm{~cm}{ }^{-2}$, therefore we use this outcome to assess a possible value of $\mathrm{V}_{\mathrm{OC}}$ and compare it with the experimental result of $0.87 \mathrm{~V}^{46}$ As shown in Table 4, our evaluation results in $\mathrm{V}_{\mathrm{OC}}=1.233 \mathrm{~V}$, thus reflecting an overestimation of the experimental value by $0.36 \mathrm{~V}$. The source of error mainly comes from $E_{c t}$ $\left(1.10 \mathrm{eV}\right.$ as determined experimentally). ${ }^{11}$ However, beyond accurate calculations, a more comprehensive analysis may be done by observing the variation of $E_{c t}$ and $k_{c r}$ as a function of $\mathrm{V}_{\mathrm{OC}}$ 
as it is depicted in Figure 2, which was made by assuming no variations in the other CT parameters. As a matter of fact, no significant fluctuations due to $E_{c t}$ can be expected for $\lambda$ since the arrangement of both nuclei and solvent mainly depends on the charge distribution of the CT state, $\mathrm{P} \mathrm{HT}^{+} / \mathrm{PCBM}^{-*}{ }^{* 4}$ Furthermore, the methodology used here for the evaluation of $\Delta G_{\text {solv }}$ via benzonitrile and, in turn, $\lambda_{e x t}$ was previously implemented by us in the triphenylamine(TPA)- $\mathrm{C}_{60}$ complex, wherein three $\mathrm{CT}$ states $\left(\mathrm{TPA}^{+\bullet}-\mathrm{C}_{60}{ }^{-*}\right)$ derived from $\mathrm{HOMO}$-to-LUMO+X transitions ( $\mathrm{X}$ $=0,1$, and 2) were described resulting in $\Delta G_{\text {solv }}=1.6 \mathrm{eV}$ in all instances..$^{39}$ Following this order of ideas, another work published by us reveals the stabilization of CT states due to the solvent, wherein $\Delta G_{\text {solv }}$ resulted in an energy range from 1.0 to $1.8 \mathrm{eV}$ for five TPA-M@C 80 endohedral metallofullerenes complexes $\left(\mathrm{M}=\mathrm{Sc}_{3} \mathrm{~N}, \mathrm{Sc}_{3} \mathrm{CH}, \mathrm{Sc}_{3} \mathrm{NC}, \mathrm{Sc}_{4} \mathrm{O}_{2}\right.$, and $\left.\mathrm{Sc}_{4} \mathrm{O}_{3}\right)$; although we found that structures containing the clusters $\mathrm{Sc}_{3} \mathrm{~N}, \mathrm{Sc}_{3} \mathrm{CH}$, and $\mathrm{Sc}_{4} \mathrm{O}_{3}$ facilitate the photoinduced charge separation reaction, TPA-[M@ $\left.\mathrm{C}_{80}\right]^{*} \rightarrow \mathrm{TPA}^{+\cdot}-\left[\mathrm{M} @ \mathrm{C}_{80}\right]^{-*}$, those complexes incorporating the $\mathrm{Sc}_{3} \mathrm{NC}$ and $\mathrm{Sc}_{4} \mathrm{O}_{2}$ clusters hamper such a reaction due to an unfavorable stabilization of the corresponding CT state. Our findings were supported by comparison with experimental redox potentials of TPA and M@ $\mathrm{C}_{80} .^{48}$ Those previous UDFT results also suggests that geometryrelaxed CT excited states are energetically similar to the corresponding Franck-Condon; at least for fullerene-based donor-acceptor complexes. On the other hand, equation 3 shows that $V_{i j}$ does change with $E_{c t}$; even though it should be noticed that the value of $V_{i j}$ mainly depends on $\mu$ since $V_{i j} \approx\left(E_{c t}\right)\left(10^{-3}\right) \approx 2 \times 10^{-3} ;$ where $10^{-3}$ comes from the division between $\mu_{i j}$ and the square root as the divisor in equation 3. Accordingly, it is noticed that an energy of $1.1 \mathrm{eV}$ for $E_{c t}$, the experimental value, leads to an increase of two orders of magnitude in the charge-recombination rate constant, $k_{c r}=9.09 \times 10^{9} \mathrm{~s}^{-1}$; this causes that $\mathrm{V}_{\mathrm{OC}}=0.80 \mathrm{~V}$, a more precise result. In addition, it can be verified from equation 1 that $J_{S C}$ has no significant impact in $\mathrm{V}_{\text {OC. }}$ That is, being $E_{c t}=1.462 \mathrm{eV}$ (the 
calculated value), $V_{O C}$ changes only $0.03 \mathrm{~V}$ when $J_{S C}$ varies from 10 to $120 \mathrm{~A} \mathrm{~m}^{-2}$. The same result is obtained in the case that $E_{c t}=1.10 \mathrm{eV}$ (the experimental value) is considered. In fact, this outcome highlights the importance of properly modeling $E_{c t}$ in organic solar cells and $k_{c r}$ since $\mathrm{V}_{\mathrm{OC}}$ is more sensitive to these parameters than is it to $J_{S C}$.

\section{Table 4. Parameters involved in the calculation of the open-circuit voltage of the P3HT/PCBM complex}

\begin{tabular}{lll}
\hline Parameter & Value & Unit \\
\hline$E_{c t}$ & 1.462 & $\mathrm{eV}$ \\
$k_{B} T$ & 0.026 & $\mathrm{eV}$ \\
$q$ & $1.60 \times 10^{-19}$ & $\mathrm{C}$ \\
$f$ & 1.00 & \\
$N_{0}$ & $1.00 \times 10^{27}$ & $\mathrm{~m}^{-3}$ \\
$L$ & $1.00 \times 10^{-5}$ & $\mathrm{~m}$ \\
$k_{c r}$ & $1.62 \times 10^{7}$ & $\mathrm{~m}^{-1}$ \\
$J_{S C}$ & 30.0 & $\mathrm{C} \mathrm{s}^{-1} \mathrm{~m}^{-2}$ \\
$V O C$ & 1.233 & $\mathrm{~V}$ \\
\hline
\end{tabular}

Overall, Figure 2 illustrates that faster charge recombination brings about a reduction of $\mathrm{V}_{\mathrm{OC}}$. Improved $\mathrm{V}_{\mathrm{OC}}$ is indeed possible by slower charge recombination; it can be reached by accessible higher-energy CT states since the term $\exp \left[-\left(\Delta G_{c r}+\lambda\right) / 4 \lambda k_{B} T\right]$ in equation 2 decreases because of $E_{c t}$. Besides, Scharber et al. had already provided an empirical expression for the estimation of the $\mathrm{V}_{\mathrm{OC}}$ by means of energy terms of the complex: $q \mathrm{~V}_{\mathrm{OC}}=E_{g}-0.3 \mathrm{eV}$ with $E_{g}$ standing for the donoracceptor energy gap. ${ }^{49}$ Even though it is a very useful tool in the design of more efficient organic solar cells, the empirical value of $0.3 \mathrm{eV}$ is an intriguing task to solve. In this regard, based on our results, equation 1 is reduced to $q \mathrm{~V}_{\mathrm{OC}}=E_{c t}-0.23 \mathrm{eV}$; a similar expression as that one derived by 
Scharber et al. In view of that, we conclude that the empirical value of $0.3 \mathrm{eV}$ should be associated to the term of equation 1 that depends on $k_{c r}$ (the second term).

Finally, not only does $E_{c t}$ play a key role in the assessment of $k_{c r}$ but also the structural variation of the P3HT/PCBM complex, as well as the accuracy of $\lambda_{\text {ext }},{ }^{50,51}$ which change $k_{c r}$ by several orders of magnitude. ${ }^{29}$ Under this order of ideas, the analysis extracted from Figure 2 is an attempt to compensate the issues related to the accurate estimation of the CT parameters significantly affecting $k_{c r}$; consequently the observation of trends should deliver better insights into the $\mathrm{V}_{\mathrm{OC}}$ of organic photovoltaics than the calculation of absolute values. Additionally, the UDFT methodology implemented in this work provides consistent results because $E_{c t}$ can be computed within an error of $0.3 \mathrm{eV}$, thus representing an advantage since energy gaps, $E_{g}$, calculated via DFT turn out to be imprecise in many cases. ${ }^{52}$ Therefore, the analysis of the computed $E_{c t}$ thru UDFT for a set of organic solar cells should provide potential complexes able to increase the efficiency of these devices.

\section{CONCLUSIONS}

In conclusion, the open-circuit voltage $\left(\mathrm{V}_{\mathrm{OC}}\right)$ is a determining factor to increase the power conversion efficiency in organic photovoltaics. The $\mathrm{V}_{\mathrm{OC}}$ depends on a variety of parameters as discussed in this work; although some of them are more relevant like the photoinduced chargetransfer occurring at the donor/acceptor interface. In this regard, the energy of charge-transfer states, $E_{c t}$, is crucial since it determines the charge-recombination rate constant, $k_{c r}$; these parameters directly affect the $\mathrm{V}_{\mathrm{OC}}$. We develop guidelines to evaluate the $\mathrm{V}_{\mathrm{OC}}$ from $E_{c t}$ mainly based on time-dependent and unrestricted density-functional-theory calculations, which represents an alternative strategy to the estimation of the $\mathrm{V}_{\mathrm{OC}}$ derived from energy gaps. The converged 
overestimations of $E_{c t}$ and $\mathrm{V}_{\mathrm{OC}}$ by $0.36 \mathrm{~V}$ as compared to the experimental values suggest that our analysis may be extended towards the investigation of more efficient organic solar cells; wherein the determination of tendencies related to the variation of $E_{c t}$ as a function of the $V_{O C}$ may be more insightful. Motivated by the results reported in this manuscript, our research group is currently devising donor/acceptor complexes concerning $E_{c t}$ and $k_{c r}$ to increase the $\mathrm{V}_{\mathrm{OC}}$.

\section{AUTHOR INFORMATION}

\section{Corresponding Authors}

*J. Pablo Martínez, e-mail: pablo.martinez@uaslp.mx

*Miquel Solà, e-mail: miquel.sola@udg.edu

\section{Notes}

The authors declare no competing financial interest.

\section{ACKNOWLEDGMENTS}

M.S. is grateful for the financial support by the Spanish Ministry of Economy and Competitivity (MINECO) (Project CTQ2017-85341-P, Network RED2018-102815-T) and the Generalitat de Catalunya (Project 2017-SGR-39, Xarxa de Referència en Química Teòrica i Computacional, ICREA Academia 2014 prize to MS). Excellent service from the computational center of the Consorci de Serveis Universitaris de Catalunya (CSUC) is acknowledged. JPM thanks financial support by a postdoctoral fellowship granted by "Programa para el Desarrollo Profesional Docente de Tipo Superior (PRODEP) (Project 201809788)" through Cuerpo Consolidado Tecnologías Aplicadas a Sistemas de Energías Renovables from the Autonomous University of San Luis Potosi. 


\section{REFERENCES}

(1) Yan, J.; Saunders, B. R. Third-Generation Solar Cells: A Review and Comparison of Polymer:Fullerene, Hybrid Polymer and Perovskite Solar Cells. RSC Adv. 2014, 4, 4328643314. https://doi.org/10.1039/C4RA07064J.

(2) Darling, S. B.; You, F. The Case for Organic Photovoltaics. RSC Adv. 2013, 3, 1763317648. https://doi.org/10.1039/c3ra42989j.

(3) O’Regan, B.; Grätzel, M. A Low-Cost, High-Efficiency Solar Cell Based on Dye-Sensitized Colloidal $\mathrm{TiO}_{2}$ Films. Nature 1991, 353, 737-740. https://doi.org/10.1038/353737a0.

(4) Sharma, K.; Sharma, V.; Sharma, S. S. Dye-Sensitized Solar Cells: Fundamentals and Current Status. Nanoscale Res. Lett. 2018, 13, 381. https://doi.org/10.1186/s11671-018$2760-6$.

(5) Li, C.-Z.; Yip, H.-L.; Jen, A. K.-Y. Functional Fullerenes for Organic Photovoltaics. J. Mater. Chem. 2012, 22, 4161-4177. https://doi.org/10.1039/c2jm15126j.

(6) Segura, J. L.; Martin, N.; Guldi, D. M. Materials for Organic Solar Cells: The $\mathrm{C}_{60} / \pi-$ Conjugated Oligomer Approach. Chem. Soc. Rev. 2005, 34, 31-47. https://doi.org/10.1039/b402417f.

(7) Thompson, B. C.; Fréchet, J. M. J. Polymer-Fullerene Composite Solar Cells. Angew. Chem. Int. Ed. 2008, 47, 58-77. https://doi.org/10.1002/anie.200702506.

(8) Guo, J.; Ohkita, H.; Benten, H.; Ito, S. Charge Generation and Recombination Dynamics in Poly(3-Hexylthiophene)/Fullerene Blend Films with Different Regioregularities and 
Morphologies. J. Am. Chem. Soc. 2010, 132, 6154-6164. https://doi.org/10.1021/ja100302p.

(9) Groves, C.; Reid, O. G.; Ginger, D. S. Heterogeneity in Polymer Solar Cells: Local Morphology and Performance in Organic Photovoltaics Studied with Scanning Probe Microscopy. Acc. Chem. Res. 2010, 43, 612-620. https://doi.org/10.1021/ar900231q.

(10) Li, G.; Shrotriya, V.; Huang, J.; Yao, Y.; Moriarty, T.; Emery, K.; Yang, Y. High-Efficiency Solution Processable Polymer Photovoltaic Cells by Self-Organization of Polymer Blends. Nat. Mater. 2005, 4, 864-868. https://doi.org/10.1038/nmat1500.

(11) Ohkita, H.; Cook, S.; Astuti, Y.; Duffy, W.; Tierney, S.; Zhang, W.; Heeney, M.; McCulloch, I.; Nelson, J.; Bradley, D. D. C.; Durrant, J. R. Charge Carrier Formation in Polythiophene/Fullerene Blend Films Studied by Transient Absorption Spectroscopy. $J$. Am. Chem. Soc. 2008, 130, 3030-3042. https://doi.org/10.1021/ja076568q.

(12) Hwang, I.-W.; Moses, D.; Heeger, A. J. Photoinduced Carrier Generation in P3HT/PCBM Bulk Heterojunction Materials. J. Phys. Chem. C 2008, 112, 4350-4354. https://doi.org/10.1021/jp075565x.

(13) Ai, X.; Beard, M. C.; Knutsen, K. P.; Shaheen, S. E.; Rumbles, G.; Ellingson, R. J. Photoinduced Charge Carrier Generation in a Poly(3-Hexylthiophene) and Methanofullerene Bulk Heterojunction Investigated by Time-Resolved Terahertz Spectroscopy. J. Phys. Chem. B 2006, 110, 25462-25471. https://doi.org/10.1021/jp065212i.

(14) Sauvé, G.; Fernando, R. Beyond Fullerenes: Designing Alternative Molecular Electron 
Acceptors for Solution-Processable Bulk Heterojunction Organic Photovoltaics. J. Phys. Chem. Lett. 2015, 6, 3770-3780. https://doi.org/10.1021/acs.jpclett.5b01471.

(15) Huang, Y.; Kramer, E. J.; Heeger, A. J.; Bazan, G. C. Bulk Heterojunction Solar Cells: Morphology and Performance Relationships. Chem. Rev. 2014, 114, 7006-7043. https://doi.org/10.1021/cr400353v.

(16) González, D. M.; Körstgens, V.; Yao, Y.; Song, L.; Santoro, G.; Roth, S. V.; MüllerBuschbaum, P. Improved Power Conversion Efficiency of P3HT:PCBM Organic Solar Cells by Strong Spin-Orbit Coupling-Induced Delayed Fluorescence. Adv. Energy Mater. 2015, 5, 1401770. https://doi.org/10.1002/aenm.201401770.

(17) Li, G.; Shrotriya, V.; Yao, Y.; Huang, J.; Yang, Y. Manipulating Regioregular Poly(3Hexylthiophene) : [6,6]-Phenyl-C61-Butyric Acid Methyl Ester Blends-route towards High Efficiency Polymer Solar Cells. J. Mater. Chem. 2007, 17, 3126-3140. https://doi.org/10.1039/b703075b.

(18) Saunders, B. R.; Turner, M. L. Nanoparticle-Polymer Photovoltaic Cells. Adv. Colloid Interface Sci. 2008, 138, 1-23. https://doi.org/10.1016/j.cis.2007.09.001.

(19) Liu, T.; Troisi, A. Absolute Rate of Charge Separation and Recombination in a Molecular Model of the P3HT/PCBM Interface. J. Phys. Chem. C 2011, 115, 2406-2415. https://doi.org/10.1021/jp109130y.

(20) Wong, W.-Y.; Wang, X.-Z.; He, Z.; Djurisić, A. B.; Yip, C.-T.; Cheung, K.-Y.; Wang, H.; Mak, C. S. K.; Chan, W.-K. Metallated Conjugated Polymers as a New Avenue towards High-Efficiency Polymer Solar Cells. Nat. Mater. 2007, 6, 521-527. 
https://doi.org/10.1038/nmat1909.

(21) Bijleveld, J. C.; Zoombelt, A. P.; Mathijssen, S. G. J.; Wienk, M. M.; Turbiez, M.; de Leeuw, D. M.; Janssen, R. A. J. Poly(Diketopyrrolopyrrole-Terthiophene) for Ambipolar Logic and Photovoltaics. J. Am. Chem. Soc. 2009, 131, 16616-16617. https://doi.org/10.1021/ja907506r.

(22) Peter, L. M. Characterization and Modeling of Dye-Sensitized Solar Cells. J. Phys. Chem. C 2007, 111, 6601-6612. https://doi.org/10.1021/jp069058b.

(23) Brédas, J.-L.; Norton, J. E.; Cornil, J.; Coropceanu, V. Molecular Understanding of Organic Solar Cells: The Challenges. Acc. Chem. Res. 2009, 42, 1691-1699. https://doi.org/10.1021/ar900099h.

(24) Martínez, J. P.; Osuna, S.; Solà, M.; Voityuk, A. Extent of Charge Separation and Exciton Delocalization for Electronically Excited States in a Triphenylamine-C60 Donor-acceptor Conjugate: A Combined Molecular Dynamics and TD-DFT Study. Theor. Chem. Acc. 2015, 134, 12. https://doi.org/10.1007/s00214-015-1614-x.

(25) Elumalai, N. K.; Uddin, A. Open Circuit Voltage of Organic Solar Cells: An in-Depth Review. Energy Environ. Sci. 2016, 9, 391-410. https://doi.org/10.1039/C5EE02871J.

(26) Marcus, R. A. Electron Transfer Reactions in Chemistry. Theory and Experiment. Rev. Mod. Phys. 1993, 65, 599-610. https://doi.org/10.1103/RevModPhys.65.599.

(27) Frisch, M. J.; Trucks, G. W.; Schlegel, H. B.; Scuseria, G. E.; Robb, M. A.; Cheeseman, J. R.; Scalmani, G.; Barone, V.; Mennucci, B.; Petersson, G. A.; Nakatsuji, H.; Caricato, M.; 
Li, X.; Hratchian, H. P.; Izmaylov, A. F.; Bloino, J.; Zheng, G.; Sonnenberg, J. L.; Hada, M.; Ehara, M.; Toyota, K.; Fukuda, R.; Hasegawa, J.; Ishida, M.; Nakajima, T.; Honda, Y.; Kitao, O.; Nakai, H.; Vreven, T.; Montgomery Jr., J. A.; Peralta, J. E.; Ogliaro, F.; Bearpark, M. J.; Heyd, J. J.; Brothers, E. N.; Kudin, K. N.; Staroverov, V. N.; Keith, T. A.; Kobayashi, R.; Normand, J.; Raghavachari, K.; Rendell, A. P.; Burant, J. C.; Iyengar, S. S.; Tomasi, J.; Cossi, M.; Rega, N.; Millam, J. M.; Klene, M.; Knox, J. E.; Cross, J. B.; Bakken, V.; Adamo, C.; Jaramillo, J.; Gomperts, R.; Stratmann, R. E.; Yazyev, O.; Austin, A. J.; Cammi, R.; Pomelli, C.; Ochterski, J. W.; Martin, R. L.; Morokuma, K.; Zakrzewski, V. G.; Voth, G. A.; Salvador, P.; Dannenberg, J. J.; Dapprich, S.; Daniels, A. D.; Farkas, Ö.; Foresman, J. B.; Ortiz, J. V.; Cioslowski, J.; Fox, D. J. Gaussian 09, revision D.01; Gaussian, Inc.: Wallingford, CT, 2009.

(28) Martínez, J. P.; Trujillo-González, D. E.; Götz, A. W.; Castillo-Alvarado, F. L.; Rodríguez, J. I. Effects of Dispersion Forces on Structure and Photoinduced Charge Separation in Organic Photovoltaics. J. Phys. Chem. C 2017, 121, 20134-20140. https://doi.org/10.1021/acs.jpcc.7b05107.

(29) Liu, T.; Cheung, D. L.; Troisi, A. Structural Variability and Dynamics of the P3HT/PCBM Interface and Its Effects on the Electronic Structure and the Charge-Transfer Rates in Solar Cells. Phys. Chem. Chem. Phys. 2011, 13, 21461. https://doi.org/10.1039/c1cp23084k.

(30) Grimme, S.; Antony, J.; Ehrlich, S.; Krieg, H. A Consistent and Accurate Ab Initio Parametrization of Density Functional Dispersion Correction (DFT-D) for the 94 Elements H-Pu. J. Chem. Phys. 2010, 132, 154104. https://doi.org/10.1063/1.3382344.

(31) Perdew, J. P.; Burke, K.; Ernzerhof, M. Generalized Gradient Approximation Made Simple. 
Phys. Rev. Lett. 1996, 77, 3865-3868. https://doi.org/10.1103/PhysRevLett.77.3865.

(32) Perdew, J. P.; Burke, K.; Ernzerhof, M. Generalized Gradient Approximation Made Simple [Phys. Rev. Lett. 77, 3865 (1996)]. Phys. Rev. Lett. 1997, 78, 1396-1396. https://doi.org/10.1103/PhysRevLett.78.1396.

(33) Tawada, Y.; Tsuneda, T.; Yanagisawa, S.; Yanai, T.; Hirao, K. A Long-Range-Corrected Time-Dependent Density Functional Theory. J. Chem. Phys. 2004, 120, 8425-8433. https://doi.org/10.1063/1.1688752.

(34) Peach, M. J. G.; Helgaker, T.; Sałek, P.; Keal, T. W.; Lutnaes, O. B.; Tozer, D. J.; Handy, N. C. Assessment of a Coulomb-Attenuated Exchange-Correlation Energy Functional. Phys. Chem. Chem. Phys. 2006, 8, 558-562. https://doi.org/10.1039/b511865d.

(35) Yanai, T.; Tew, D. P.; Handy, N. C. A New Hybrid Exchange-correlation Functional Using the Coulomb-Attenuating Method (CAM-B3LYP). Chem. Phys. Lett. 2004, 393, 51-57. https://doi.org/10.1016/j.cplett.2004.06.011.

(36) Darling, S. B.; Sternberg, M. Importance of Side Chains and Backbone Length in Defect Modeling of Poly(3-Alkylthiophenes). J. Phys. Chem. B 2009, 113, 6215-6218. https://doi.org/10.1021/jp808045j.

(37) Barone, V.; Cossi, M. Quantum Calculation of Molecular Energies and Energy Gradients in Solution by a Conductor Solvent Model. J. Phys. Chem. A 1998, 102, 1995-2001. https://doi.org/10.1021/JP9716997.

(38) Cossi, M.; Rega, N.; Scalmani, G.; Barone, V. Energies, Structures, and Electronic 
Properties of Molecules in Solution with the C-PCM Solvation Model. J. Comput. Chem. 2003, 24, 669-681. https://doi.org/10.1002/jcc.10189.

(39) Martínez, J. P.; Solà, M.; Voityuk, A. A. Theoretical Estimation of the Rate of Photoinduced Charge Transfer Reactions in Triphenylamine $\mathrm{C}_{60}$ Donor-Acceptor Conjugate. J. Comput. Chem. 2016, 37, 1396-1405. https://doi.org/10.1002/jcc.24355.

(40) Moulé, A. J.; Meerholz, K. Interference Method for the Determination of the Complex Refractive Index of Thin Polymer Layers. Appl. Phys. Lett. 2007, 91, 061901. https://doi.org/10.1063/1.2767232.

(41) Hoppe, H.; Shokhovets, S.; Gobsch, G. Inverse Relation between Photocurrent and Absorption Layer Thickness in Polymer Solar Cells. Phys. status solidi 2007, 1, R40-R42. https://doi.org/10.1002/pssr.200600011.

(42) Cave, R. J.; Newton, M. D. Calculation of Electronic Coupling Matrix Elements for Ground and Excited State Electron Transfer Reactions: Comparison of the Generalized MullikenHush and Block Diagonalization Methods. J. Chem. Phys. 1997, 106, 9213-9226. https://doi.org/10.1063/1.474023.

(43) Marcus, R. A. On the Theory of Oxidation-Reduction Reactions Involving Electron Transfer. I. J. Chem. Phys. 1956, 24, 966. https://doi.org/10.1063/1.1742723.

(44) Lee, M. H.; Dunietz, B. D.; Geva, E. Calculation from First Principles of Intramolecular Golden-Rule Rate Constants for Photo-Induced Electron Transfer in Molecular DonorAcceptor Systems. J. Phys. Chem. C 2013, 117, 23391-23401. https://doi.org/10.1021/jp4081417. 
(45) Lee, M. H.; Geva, E.; Dunietz, B. D. Calculation from First-Principles of Golden Rule Rate Constants for Photoinduced Subphthalocyanine/Fullerene Interfacial Charge Transfer and Recombination in Organic Photovoltaic Cells. J. Phys. Chem. C 2014, 118, 9780-9789. https://doi.org/10.1021/jp501199u.

(46) Yue, G.; Wu, J.; Xiao, Y.; Ye, H.; Lin, J.; Huang, M. Flexible Dye-Sensitized Solar Cell Based on PCBM/P3HT Heterojunction. Chinese Sci. Bull. 2011, 56, 325-330. https://doi.org/10.1007/s11434-010-3080-0.

(47) Nelsen, S. F.; Blackstock, S. C.; Kim, Y. Estimation of Inner Shell Marcus Terms for Amino Nitrogen Compounds by Molecular Orbital Calculations. J. Am. Chem. Soc. 1987, 109, 677-682. https://doi.org/10.1021/ja00237a007.

(48) Martínez, J. P.; Solà, M.; Voityuk, A. A. The Driving Force of Photoinduced Charge Separation in Metal-Cluster-Encapsulated Triphenylamine-[80]Fullerenes. Chem. Eur. J. 2016, 22, 17305-17310. https://doi.org/10.1002/chem.201603504.

(49) Scharber, M. C.; Mühlbacher, D.; Koppe, M.; Denk, P.; Waldauf, C.; Heeger, A. J.; Brabec, C. J. Design Rules for Donors in Bulk-Heterojunction Solar Cells-Towards 10 \% Energy$\begin{array}{llllll}\text { Conversion } & \text { Efficiency. } & \text { 2006, } & \text { Mater. } & \text { 18, } & \text { 789-794. }\end{array}$ https://doi.org/10.1002/adma.200501717.

(50) McMahon, D. P.; Troisi, A. Evaluation of the External Reorganization Energy of Polyacenes. J. Phys. Chem. Lett. 2010, 1, 941-946. https://doi.org/10.1021/jz1001049.

(51) Norton, J. E.; Brédas, J.-L. Polarization Energies in Oligoacene Semiconductor Crystals. $J$. Am. Chem. Soc. 2008, 130, 12377-12384. https://doi.org/10.1021/ja8017797. 
(52) Morales-García, Á.; Valero, R.; Illas, F. An Empirical, yet Practical Way To Predict the Band Gap in Solids by Using Density Functional Band Structure Calculations. J. Phys. Chem. C 2017, 121, 18862-18866. https://doi.org/10.1021/acs.jpcc.7b07421. 
Table of Contents (TOC). Organic Photovoltaics in electronic devices.

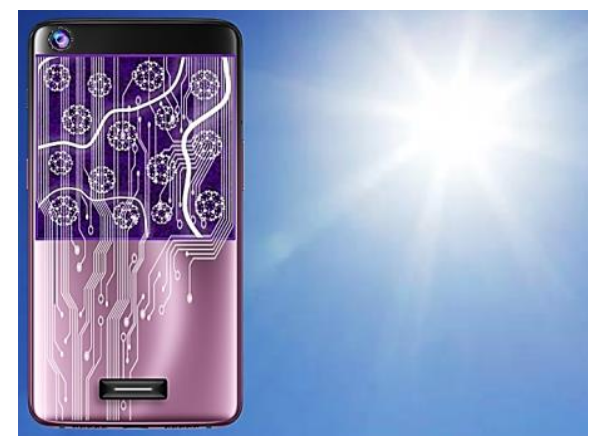

